\title{
Analyzing the functional capabilities of modern systems, methods and means for scheduling
}

\author{
Sergey Sinenko* \\ Moscow State University of Civil Engineering, Department of Construction Technology and \\ Organization, 129337 Moscow, Russian Federation
}

\begin{abstract}
This work deals with the approaches for scheduling the process of territory development with building complexes of any objects being erected or reconstructed in sequence based upon up-to-date software products, provides the analysis of the functional capabilities of systems, methods and means for scheduling and gives an overview of modern software for scheduling.
\end{abstract}

\section{Significance of long-term scheduling in construction}

At present major megapolises worldwide are actively applying the method of territory development with building complexes including the city centres development, often using reconstruction and restoration resulting in adapting for residence or commercialization any premises in the existent erections [1].

In the current context of present-day competition improvement the principal participants of investment and construction activities shall effectively arrange construction operations to receive maximum profit at minimal cost of time and resources without any failures as to construction deadlines causing expenses increasing in the course of projects implementation and loss of profit for all participants of construction and investment activities.

Building a complex of objects shall require long-term scheduling and consequently may be faced by the goal of generating long-term investment construction spreads including the matter of optimizing the sequence of building complex objects development. Hence, it requires the tools enabling to select the construction appropriate sequence being at the same time resistant to perturbing factors. At present this matter may only be settled at the level of methodological foundation of rather general nature indicating that requires to address the goals focused on modern tolls basis for effective scheduling [2].

\section{Effective scheduling}

\subsection{Goals for scheduling, basic definitions}

Scheduling refers to the fundamentals of management and is applied in various sectors: power generation sector, oil and gas sector, metallurgical industry, construction, etc. The

\footnotetext{
*Corresponding author: 6622040@mail.ru
} 
reason for scheduling development is the projects complexity increasing and necessity of raising the efficiency of implementing thereof. Construction companies face the goal of optimal distribution of limited resources in time. Investment and construction project is a complex system shifting from one stage to another one in the course of its whole life cycle. Such stages are referred to as the project phases, and each of them has its specific features and risks, so projecting methods for scheduling at various stages shall be different $[3,4]$.

\subsubsection{Stages of an object building process}

At the first (pre-investment) stage of an object building since the deficiency of information about the project the scheduling shall be projected taking into consideration any available consolidated indices addressing the following goals: estimating the project's efficiency and feasibility, fixing the project's term and cost thereof, developing the process of investing into the project.

An investment stage is the main project's stage including negotiations holding and contracts making, projecting, construction, marketing. In the course of bidding scheduling enables to receive the most preferable tender bid addressing the goals as follows: scheduling the milestones for the works to be performed, building a financing schedule, executing statements for personnel and physical resources required.

For the purposes of scheduling it may be divided into 2 steps: the process of the project development and its implementation supervising. The first step includes the goals as follows: defining the scope of work, executing schedules for the works and costs, timelines development, resources allocation, estimating and optimizing the milestones, constructing the charts for needs in personnel resources and machines, arranging the schedule of materials procurement and supply, estimating the costs at various stages and risks evaluation [5].

\subsubsection{Modern systems for scheduling}

In accordance with the goals faced by scheduling at present there is a number of modern systems that shall have capabilities as follows:

- organizational and technological diagram creation including describing the global parameters of the project scheduling, describing the structure of the scope of works, supporting the project calendar;

- settlement means subject to the critical path method (being the derivative of organizational and technological diagram);

- resource planning means (supporting the resources calendars, resources destination, calendar scheduling with limited resources, making the list of resources and costs items);

- supervising means for the project implementation process (recording targeted parameters of the project's timelines, entering actual parameters of the set goals, comparing scheduled and actual parameters, forecasting the outstanding works fulfilment);

- means for preparing reports and graphical presentation of the project's structure (by means of Gannt Chart, network diagram, PERT diagram);

- means for costs analysis [6].

\subsection{Scheduling with the help of software packages}

At present the market offers a majority of universal software packages that we are used to subdivide into professional and "desktop" (amateur). They mainly differ in the labor intensity when applying since professional software is quite time-consuming however it may provide more flexible outcome, and amateur packages may be used just once, and spending little time and few efforts you shall receive quite an informative result. 
Except for universal programs, in more recent times extra software packages are widely distributed enabling to treat each project much more individually. They address the goals as follows:

- risks analyzing, planning the best strategy for risks management (@RISK by Palisade Corp.);

- timeline scheduling subject to the goals, salary accounting (HMS Software, Time Control);

- timeline scheduling in the course of limited resources (Best Schedule for Project by Parsifal System Inc.);

- integrating the management system into corporate systems (Project Gateway by Marin Research Inc., Project Management Integrator by Time Line Solutions Corp., etc.) [7].

The most applicable universal professional software packages with the cost of more than $1000 \$$ are Artemis Project View, Open Plan Professional, Primavera Project Planner.

Among the amateur universal software packages the most frequently used are OpenPlanDesktop, Project 98, Project Scheduler, Super Project, Time Line.

\section{Applying Open Plan Professional when projecting scheduling}

In respect that the sectioning the software depending on the outcome that is required let consider the key features of Open Plan Professional Software Complex as a system being among the leaders in the sphere of professional systems for projects management (Figure 1) [8].

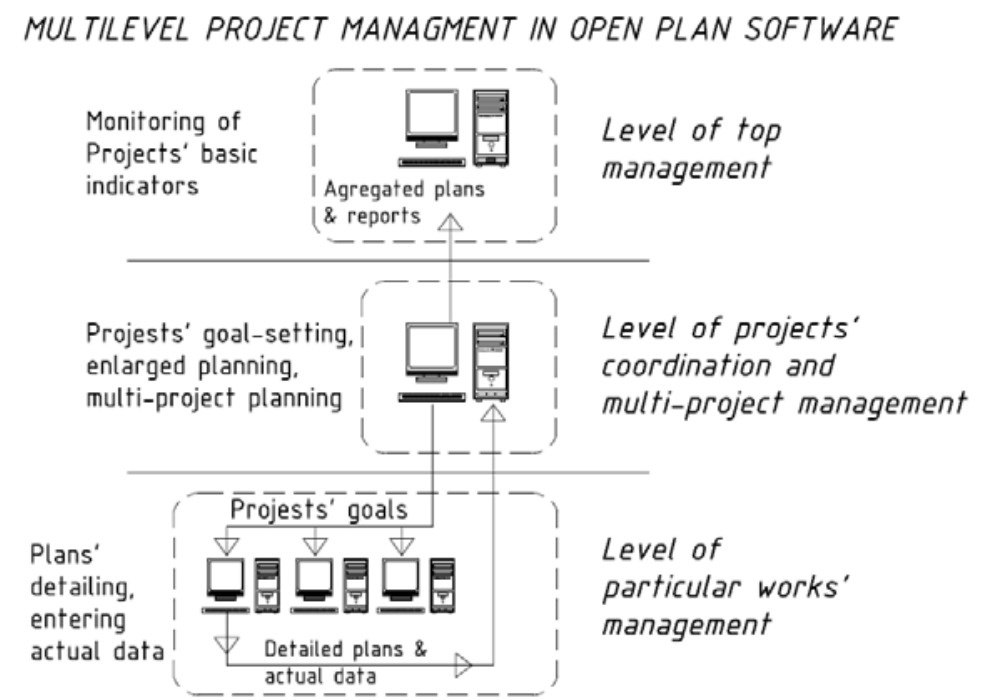

Fig. 1. Projects' management system in Open Plan Software.

\subsubsection{The software package primary function and its capabilities}

Open Plan Professional refers the category of professional software packages and correspondingly possesses powerful features of resource and cost planning. In this context it's recommended to apply it for major projects requiring detailed scheduling and for integration with other organization automated systems. 


\subsubsection{Software functional capabilities}

The software enables to create a resource breakdown structure and enables to automatically allocate resources among the goals subject to qualification thereof. It also enables to analyze risks, calculate the probability thereof and any consequences subject to any possible delays in the materials delivery, budget deficit.

\subsubsection{Further capabilities for resources management}

Open Plan's powerful features for resources planning enable to properly manage any types of resources: human, equipment, materials, finance (Figure 2) [9].

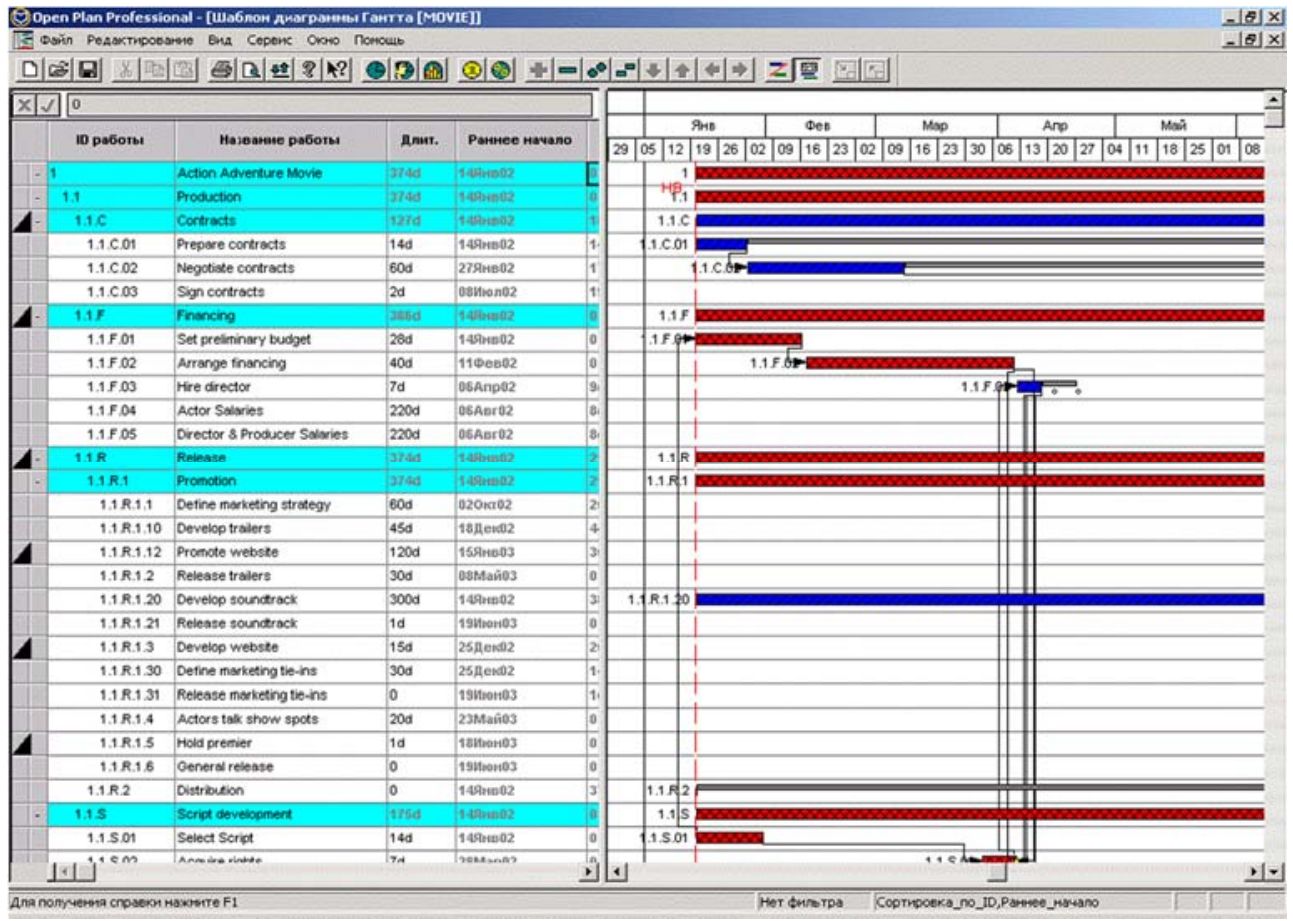

Fig. 2. Resources management in open plan professional.

\subsubsection{Costs analyzing}

The software enables to create a resource breakdown structure and enables to Open Plan provides for special procedures for costs scheduling and supervising particularly noting the means of analyzing and building reports for actual output. The facilities for "memorizing" several options of any project implementation and inputting the actual data regarding costs for work and resources workout enable to analyze the project costs both forecast and actual [10].

\subsubsection{Risks Analysis}

Analytical tools built in Open Plan enable to evaluate any probable risks in estimating the term of separate works, whole stages and the whole project completion, using the facilities as follows:

- procedures of inputting probability distribution for any selected or all project's works; 
- analyzing the risks subject to Monte Carlo Methods to estimate the probabilities input into the project's dates;

- providing the reports being used to analyze the uncertainties influence on the project's implementation [11].

\subsubsection{Multi-project analysis}

Open Plan's standard facilities enable to integrate independent projects enabling to manage resources and finance taking into consideration the projects' priority being implemented by any company and receiving the consolidated statements (Figure 1).

\subsubsection{Means for creating the project's model}

The project's structuring is one of the key concepts of the management concepts due to which the project's hierarchic subdivision into components is provided that are much easier to schedule and supervise. Comparing to other professional systems of the projects scheduling and management, Open Plan provides the most powerful present-day project's models based on the following basic concepts:

- goals hierarchic structure (WBS -Work Breakdown Structure);

- network model (PERT Diagram represented at Figure 3);

- resources hierarchic structure;

- hierarchic system of activities coding [12].

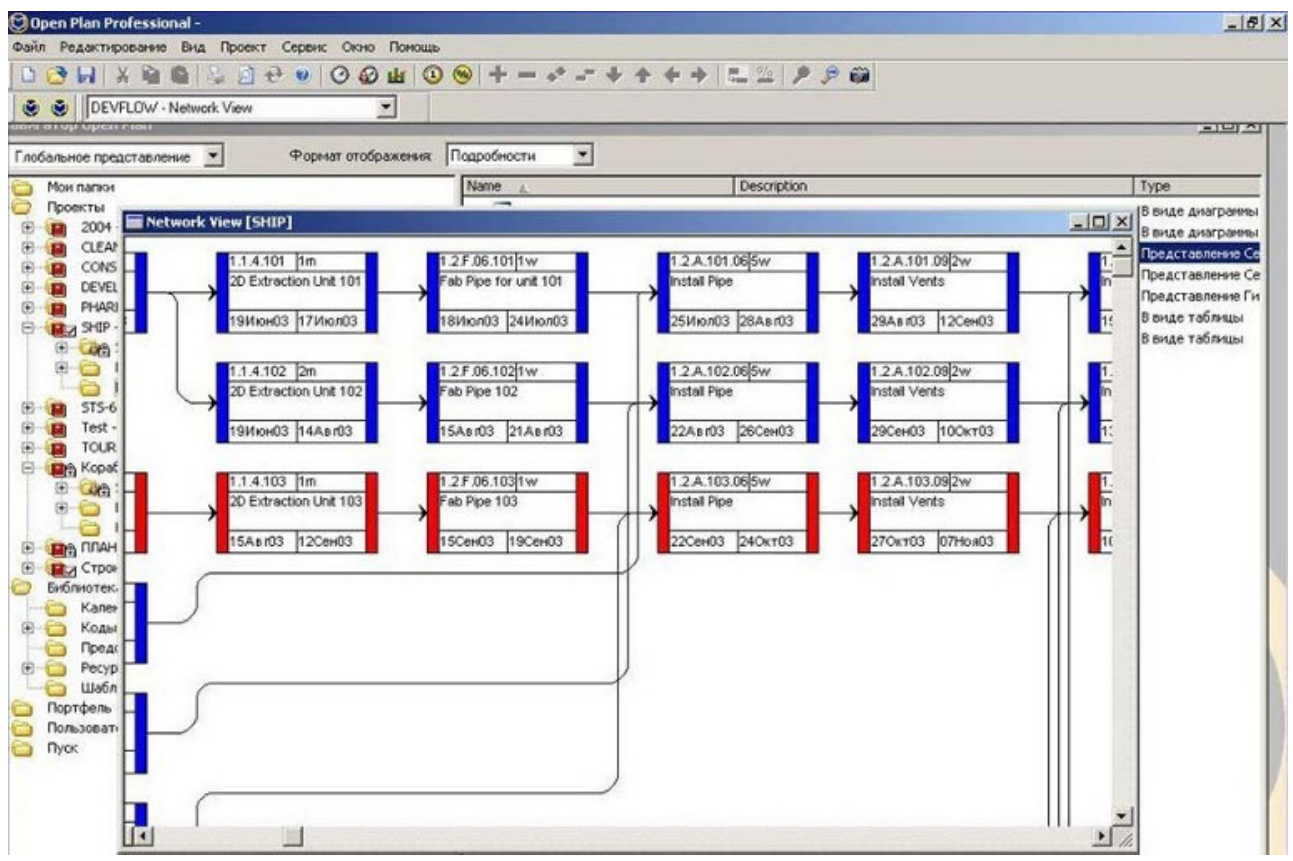

Fig. 3. Network model view in Open Plan Software.

\subsubsection{Multi-project planning}

Operations opportunities in Open Plan in multi-project mode enable users to consider one major project as consisting of much smaller sub-projects providing thereby flexible management at various levels. 
Working in multi-project mode provides facilities to supervise and distribute unified company's data among all projects being implemented by it. Uniting projects in such a way serves two purposes at once: firstly, analyzing the resources loading on a scale of the whole company, secondly, providing the environment for integrated software-based control of large complex projects subdivided into sub-projects $[13,14]$.

\section{Conclusion}

Following the results of the study it's reasonable to make the following conclusions:

1. Building a complex of objects shall require long-term scheduling and consequently there arise the goals of forming long-term construction spreads including the matter of optimizing the priority of developing the objects being the part of a building complex.

2. There is a number of modern ways, methods and means for scheduling enabling to settle various goals and aiding the development of scheduling methods; at the same time there are universal software packages, separate programs and applications enabling to settle general and more specific goals of scheduling. In this angle Open Plan is deemed one of the leaders in the sphere of professional systems of projects management.

3. Open Plan Software greatly facilitates solving management tasks at the construction site. Implementing this software in the construction management processes may help to avoid many complexities and details, among the house erecting could be planned using the newest materials and technologies. The great advantage of the software is the regulatory framework based of including the basic regulations for management and technologies of construction operations. It makes it possible to implement the most rational construction process.

\section{References}

1. B.V. Zhadanovsky, S.A Sinenko, Science Review 9-2, 435 (2014)

2. B.V. Zhadanovsky, D.G. Dragan, S.A Sinenko, Tech. and org. of build. prod. 2, 38 (2014)

3. S.O. Novikov, B.V. Zhadanovsky, Science Review 21, 341 (2015)

4. B.V. Zhadanovsky, S.A. Sinenko, AMR 838-841, 280 (2013)

5. V.S. Semenov, E.V. Tkach, S.A. Tkach, T.A. Rozovskaya, Proc. Eng. 111, 763 (2015)

6. A.A. Volkov, V.O. Chulkov, R. Kazaryan, M.A. Fachratov, O.N. Kyzina, R.K. Gazaryan, AMM 580, 2281 (2014)

7. S.O. Novikov, A.A. Sapukhin, Proc. of MSUCE 7, 96 (2013)

8. V.O. Chulkov, R.K. Gazaryan, V. M. Fakhratov, A.V. Belyaev, Proc. of VGASU 23, 91 (2012)

9. S.O. Novikov, Matec Web of Conf. 86, 04032 (2016)

10. P.P. Oleinik, Proc. Eng. 153, 208 (2016)

11. E.K. Zavadskas, T. Vilutienè, Z. Turskis, J. Šaparauskas, ACME 14, 114 (2014)

12. D. Jato-Espino, E. Castillo-Lopez, J. Rodriguez-Hernandez, J.C. Canteras-Jordana, AutoCon 45, 151 (2014)

13. A.A. Lapidus, Proc. of MSUCE 7, 96 (2013)

14. P. De Wilde, D. Coley, Build. and Env. 55, 1 (2012) 